\title{
Semiotic Conflicts in the Learning of Proportionality: Analysis of a Teaching Experience in Primary Education
}

\author{
María Burgos ${ }^{1 *}$, Juan D. Godino ${ }^{1}$ \\ ${ }^{1}$ Universidad de Granada, SPAIN \\ *CORRESPONDENCE: $\square$ mariaburgos@ugr.es
}

\begin{abstract}
In this paper, we analyse the results of an experience designed and implemented to evaluate the epistemic and cognitive conflicts identified in the study of proportionality, carried out by a group of 21 students in their last year of primary education. Initially the students exhibit difficulties to recognize situations where proportionality can be applied, to distinguish magnitudes, quantities and proportionality tables, and to identify procedures to solve proportionality problems other than the rule of three. Nevertheless, in the group discussion session, oriented to develop the dialogue and collective justification of the assessment tasks solutions, they are able to justify the methods employed, linking the rule of three with the equivalence of fractions and the proportionality relation.
\end{abstract}

Keywords: learning, proportionality, primary education, didactic models, epistemic and cognitive conflicts

\section{INTRODUCTION}

Developing proportional reasoning since its beginning in primary education and its continuity in secondary education has been the subject of intense attention by mathematics education researchers (Fernández \& Llinares, 2012; Fielding-Wells, Dole \& Makar, 2014; Hilton, Hilton, Dole \& Goos, 2016; Karplus, Pulos \& Stage, 1983; Lamon, 2007; Lesh, Post \& Behr, 1988; Modestou \& Gagatsis, 2010; Sánchez, 2013). Authors agree with the idea that proportional reasoning implies mathematical knowledge to solve specific types of problems, involving both the understanding of mathematical objects at stake and the justification of the properties and procedures required.

Various reasons, among which there may be a poor preparation of teachers, can lead to the fact that, in the case of proportionality, the teaching actually implemented is biased towards rote learning of the rule of three algorithm. Teachers often tend to rely on the algorithm of the rule of three or cross multiplication in situations of proportionality, without reasoning their pertinence (Riley, 2010; Singh, 2000) and sacrificing the development of conceptual understanding (Lamon, 2007). This position is reinforced by the approach given in textbooks to the study of proportionality.

Fernández, Caballero and Fernández (2013) performed an analysis of 6th grade Spanish primary school mathematics textbooks focused on conceptual errors (ambiguous descriptions of algorithms, contents where restriction conditions are omitted, solutions where wrong concepts are applied) present both in the contents and in the solved and proposed exercises. The authors conclude the urgency of investigate what is being taught, as well as, to what extent these errors have an impact on student learning. In this sense, in his research on

Article History: Received 12 February $2020 \bullet$ Revised 27 March $2020 \bullet$ Accepted 7 April 2020

(C) 2020 by the authors; licensee Modestum Ltd., UK. Open Access terms of the Creative Commons Attribution 4.0 International License (http://creativecommons.org/licenses/by/4.0/) apply. The license permits unrestricted use, distribution, and reproduction in any medium, on the condition that users give exact credit to the original author(s) and the source, provide a link to the Creative Commons license, and indicate if they made any changes. 
the use of the book by students, Rezat (2010) obtained that students not only use the mathematics textbook when the teacher tells them to do so; they also use the textbook on their own initiative and autonomously.

Guacaneme (2001) investigated the role of the proportion and proportionality concepts in school mathematics textbooks. In this regard, he affirmed that there are concepts that are not explicitly or implicitly defined in school texts, but they are nevertheless used to explain and characterize the types of proportionality. He also noted that all the textbooks analysed develop a treatment of ratio as a number and to address the proportionality study do not establish explicit relationships between the arithmetic approach of ratio and proportion and the context of magnitudes.

Following the theoretical-methodological tools of the Ontosemiotic Approach (OSA) of mathematical knowledge and instruction (Godino, Batanero \& Font, 2007; 2019), in Burgos, Castillo, Beltrán-Pellicer, Giacomone and Godino (2020) a didactic analysis was carried out of a lesson on proportionality of a 6th grade primary education textbook, based on a previous review of didactic-mathematical knowledge about this content. Considering that a lesson reflects the instructional process planned by the author as a means to achieve the learning of the content by potential students, their analysis allowed to identify several epistemic, cognitive and instructional conflicts: 1) it is not made explicit in the lesson that the ratio between the quantities of proportional magnitudes must always be the same (proportionality constant), 2) an algorithmic orientation that seeks to acquire skill in the application of the unit reduction method routine or the degenerate rule of three (that is, for solving a proportionality problem it is enough to put the four values in a $2 \times 2$ table, multiply two numbers and divide by the third), 3) lack of arguments/justifications of the procedures and propositions involved, 4) absence of situations that allow to reflect on whether the relationship in a problemsituation is multiplicative or additive.

Assuming that a mathematics teacher has decided to use a textbook lesson with these characteristics as a resource to support the teaching and learning process of proportionality, our research is guided by the following question:

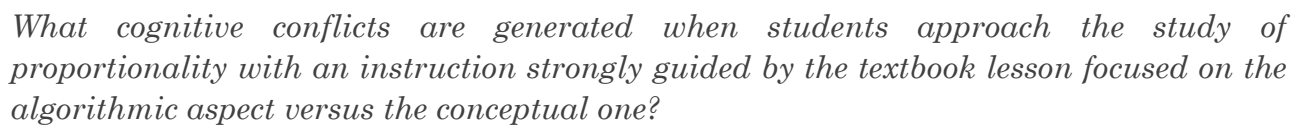

To answer this question, we have carried out a didactic intervention with sixth grade primary education students whose design, implementation and results we report in this article. The experience has taken place in a special context that has revealed some relevant cognitive and didactic phenomena. The intervention was developed after the students had finished the study of proportionality with a methodology based on the use of the textbook. The lesson used as an instruction guide was the same analysed in Burgos, Castillo et al. (2020). This allows us to reveal some conflicts of meaning that should be taken into account when it is intended that students develop proportional reasoning, which requires, on the one hand, that procedural knowledge be enriched with the understanding of the concepts and properties involved, and by another, that the justification of the answers to the proposed tasks be favoured.

This paper is organized in the following sections: in Section 2 we describe the theoretical framework and the background of the research problem; Section 3 includes the methodological approach. Section 4 analyses the epistemic conflicts associated with the instructional process. Section 5 includes the results on the students' knowledge assessment and the cognitive conflicts identified. The description and analysis of results of the large group discussion session is included in section 6. Section 7 includes the analysis in terms of the epistemic and cognitive conflicts, as well as some final reflections derived from what was observed in the general discussion session.

\section{THEORETICAL FRAMEWORK AND BACKGROUND}

In this article we apply some theoretical tools of the Ontosemiotic Approach (OSA) of mathematical knowledge and instruction (Godino et al., 2007, Godino et al. 2019) to raise the problem and interpret the data collected on the experience implemented.

\section{Meanings and Semiotic Conflicts}

Two OSA key notions are those of meaning (understood as a system of practices) and onto-semiotic configuration of practices, objects and processes. Both allow describing mathematical activity, from the institutional (or epistemic) and personal (or cognitive) point of view. The institutional (respectively, personal) 
meaning of a mathematical object is identified with the system of operative and discursive practices that within an institution (respectively, a person) performs to solve the types of problems from which the object emerges at a given time. In the OSA different categories of objects are introduced according to their nature and the role they play in the mathematical practices in which they intervene: languages (terms, expressions, notations, graphs) in their various registers (written, oral, gestural, etc.), problem-situations (extra or intramathematical applications, exercises), concepts (introduced through definitions or descriptions, such as line, number, function), propositions (statements about concepts), procedures (algorithms, operations, calculation techniques) and arguments (statements used to validate or explain the propositions and procedures).

To plan an instructional process on a mathematical object for a group of students, the teacher or researcher should consult the corresponding mathematical texts and curricular orientations, in order to delimit the system of operative and discursive practices inherent to the object, which are considered as the object institutional reference meaning. The system of practices that is implemented in the mathematics class, and which will be the immediate reference for assessing the student's learning, is called the implemented institutional meaning.

In the OSA, the notion of semiotic conflict is introduced as "a disparity or mismatch between the meanings attributed to the same expression by two subjects - people or institutions - in communicative interaction and can explain the difficulties and limitations of the learnings achieved and the teachings implemented" (Godino, 2002 , p. 258). When the mismatch occurs between institutional meanings (for example, between the reference meaning and that one implemented in a textbook or by a teacher) it is an epistemic conflict, while if the disparity takes place between the meaning manifested by a subject and the reference meaning, it is a cognitive conflict. Semiotic conflicts may involve one or several of the types of primary mathematical objects considered in the OSA, so there are representational, situational, conceptual, procedural, propositional and argumentative semiotic conflicts.

\section{Reference Meaning of Proportionality}

From the epistemic perspective, proportionality has been studied according to three points of view: the arithmetic (centred on the notions of ratio and proportion), the algebraic (focused on the notion of function), and the geometric (focused on the notion of similarity) points of view. From the arithmetic approach, two categories of problems are essentially distinguished: comparison (four values are given forming two ratios, two-to-two multiplicatively related) and missing value (the proportion is an equality relationship between two ratios, in which one of the terms is an unknown value).

An algebraic-functional approach of proportionality assumes that proportional reasoning implies a type of "reasoning in a system of two variables between there exists a linear functional relationship" that "leads to conclusions about a situation or phenomenon that can be characterized by a constant ratio" (Karplus et al., 1983, p. 219). The mathematical model that responds to this situation is a function $y=k x$, where $k$ is the unit constant ratio or proportionality constant.

The universe of proportionality meanings can be classified according to different criteria, such as the field of application, which involves specific objects and processes of problem-solving practices linked to these contexts, or the level of algebrization of mathematical practices involved, as Godino, Beltrán-Pellicer, Burgos and Giacomone (2017) propose. These authors distinguish three types of proportionality meanings: arithmetic (characterized by the application of arithmetic calculation procedures), proto-algebraic (focused on the notion of proportion) and algebraic-functional (where the notion and properties of linear function intervene). These three meanings are also complemented by an informal-qualitative meaning, focused on the multiplicative comparison of the quantities involved in the problems and the perceptual comparison, for example, of geometric shapes similarity.

\section{Introduction of Proportional Reasoning in Primary Education}

Several authors propose to anticipate an informal, intuitive and qualitative approach to the concept of ratio and proportion prior to its formalization and algorithmization (Streefland, 1985; Lesh, Post \& Behr, 1988; Cramer \& Post, 1993; among others). It is considered essential to include in the instructional processes both proportional and non-proportional situations (for example, situations that reflect on whether the relationship in a problem-situation is multiplicative or additive) and provide students with the opportunity to distinguish both types of situations (Dole \& Shield, 2008; Fernández \& Llinares, 2011). 
Task 1. With three kilograms of corn my chickens eat 6 days. How many kilograms of corn will I need for 30 days? Explain your answer.

Task 2. Laura and Sofia want to paint their rooms in the same colour. Laura mixes 3 cans of yellow paint and 6 of red paint. If Sofia has used 7 cans of yellow paint, how many cans of red paint will she need? Explain your answer.

Task 3. To go to school, students use two means of transport. For every student who goes by car there are three who go on foot. If there are 212 students in the school, how many students use each means of transport? Explain your answer.

Task 4. A bookstore applies the same discount to all its articles if you present the AMPA card of Fuenfría School. If for a book of 30 euros I paid 25.5 euros:

a) How much will I pay for a book of 20 euros?

b) I paid 34 euros for the Idhún comic collection. What was its initial price?

c) What percentage of discount do they apply to children of Fuenfría?

Explain how you obtained each result.

Figure 1. Statements of the proposed tasks

For Lamon (2007) proportional reasoning lies in the recognition of the constant relationship between elements of the same measurement space and the recognition of the functional relationship between different measurement spaces (p. 638). It implies the ability to recognize a multiplicative relationship between two quantities, as well as the ability to extend the same relationship to other pairs of quantities. This involves the need to propose situations in which students have to make multiplicative comparisons by formulating conclusions about these comparisons.

The teacher plays a decisive role in promoting proportional reasoning in the early educational stages. Silvestre and Ponte (2011) assume in their didactic experience that the learning of direct proportionality in the 6th year of schooling should focus on understanding the multiplicative structure of a proportional relationship, developed by solving problems in the context of social interaction in small groups and collective discussion in the whole class. Bentley and Yates (2017) carry out a comparative study of the results obtained by two groups of 12-year-old students, when they solved problems that required proportional reasoning and defended the relevance of an instructional model based on step-by-step examples of reduction to unit. Burgos and Godino $(2018,2019)$ describe the results of a teaching experiences of introduction proportionality to 5th grade primary education students, in which they explore the didactic conditions, through a mixed-type instructional model, which allow to recognize and promote early forms of algebraic reasoning in the students' practices when they face direct proportionality tasks for the first time.

\section{METHOD AND CONTEXT}

In this research work, we use a specific methodological approach to design research (Kelly, Lesh \& Baek, 2008) or didactic engineering (Artigue, 2011) based on the application of OSA theoretical tools (Godino, Rivas, Arteaga, Lasa \& Wilhelmi, 2014). It is assumed that educational research separated from practice may not take into account the influence of contexts on the complex nature of the results, or may not adequately identify constraints and conditioning factors, so the focus is on the learning achieved in a real class context.

The experience that we describe in this paper was carried out in a public school for primary education in Spain during the 2017-2018 academic year. The sample under study consists of a group of 21 students (12 girls and 9 boys) of the sixth year of primary education (11-12 years-old).

The training intervention was carried out in 3 sessions of 45 minutes at the beginning of the third trimester. Previously the students had studied the subject "Proportionality and Percentages" and had been evaluated by their teacher, without very good results from the group teacher's opinion. For collecting the information related to the experience, the responses of each student to the proposed tasks (Figure 1), the audio recording of the sharing session and the reporting of students' observations in the different sessions were used. 


\section{EPISTEMIC CONFLICTS}

Pupils studied the topic "Percentages and proportionality" in the last two weeks of the second semester. In the instruction, the course teacher had followed the mathematics textbook of Ferrero, Martín, Alonso and Bernal (2015). At the beginning of each class session, a student designated by the teacher (following an order for everyone to participate) read the theoretical explanation corresponding to the content they were going to discuss. Next, the teacher asked if any student had doubts and if they did not have, he indicated the problems they had to make in each lesson section. Although the students usually did not ask, to clarify their doubts when there were any, the teacher selected some of the problems to solve on the electronic board. In general, the students solved all the problems in the lesson, except those used by the teacher to clarify doubts (a problem to explain the rule of three) or the book section "Mathematical challenges".

Given that the textbook lesson reflects the instruction received by the students, we briefly summarize the way in which the concepts and procedures related to proportionality were presented:

- Two magnitudes are defined as directly proportional "when multiplying, or dividing, one of them by a number, the other is multiplied or divided by that same number". No mention is made of the proportionality constant.

- The reduction to the unit method is presented as "a procedure to solve proportionality problems in which, first, there is the quantity that corresponds to a unit and then it is multiplied by the number of units". Only three problems are dedicated to working this content.

- Then the rule of three is defined as "another procedure to solve problems of direct proportionality, which consists in calculating one of the four values if the other three are known". Three steps are presented to apply a rule of three:

1. "The data are collected in a proportionality table". It is a table of two rows (one by each magnitude) and three columns: the first column for the names of the magnitudes, the second for two known values of these, and the third for a known value and the unknown of the other (second row), denoted by $x$.

2. They express "the proportionality table as a pair of equivalent fractions". The proportion is established, from the previous table.

3. "The missing term, $x$ " is calculated. At this time the unknown value is obtained by cross multiplication but without giving any justification.

- The last section of the topic is dedicated to the definition and calculation of percentages. The percentage is defined as "a fraction with denominator 100" and the calculation of percentages is obtained by using the fraction as operator.

The problems related with the concept of directly proportional magnitudes were raised in terms of proportionality tables. The theoretical explanation highlighted the multiplicative relationship between quantities of the same magnitude and not between corresponding quantities of different proportional magnitudes, so that the scalar relationship is prioritized over the functional one. The proportionality constant is not introduced.

In the textbook, the rule of three is presented as a procedure to solve missing value problems (the unit reduction procedure is hardly considered). All the proposed problems are of this type, except for one of mixtures that appears in the mathematical challenge section (it was not corrected in class). Discussing the proportionality relationship between the magnitudes and the argument that justifies the procedures are left in the background.

In general, the implemented institutional meaning is not consistent with the reference meaning established in the curricular orientations and to what experts consider to be the operative and discursive practices inherent to proportional reasoning (section 2.2). The conceptual aspects are neglected, focusing exclusively on the application of a routine procedure; the teaching did not give students the possibility of interpreting and exchanging information, or explaining the meaning of the data, and discussing whether in the situation presented were pertinent to apply the proportionality model. Specifically, we identify the following epistemic conflicts:

EC1. Direct proportionality correspondence is defined by means of the scalar relationship; any mention is made to the functional relationship established between the magnitudes. 
EC2. There are hardly any opportunities to distinguish proportional from nonproportional situations nor does the lesson include a prior intuitive approach.

EC3. The rule of three is presented as a means to calculate one of the four values if the other three are known, without discussing whether it is pertinent to apply the proportionality model.

EC4. The rule of three is linked to the proportionality table; the expression of the proportionality table as a pair of equivalent fractions is established as one of the procedure steps.

EC5. The scope of proportionality is reduced only to missing value problems.

EC6. The study of percentages is established without connection with proportionality, applying only a procedural point of view.

$\underline{\text { Table 1. Correction degree frequencies of problem solutions }}$

\begin{tabular}{|c|c|c|c|c|c|c|}
\hline \multirow{2}{*}{ Correction degree } & \multicolumn{6}{|c|}{ Problem } \\
\hline & 1 & 2 & 3 & 4 a) & $4 \mathrm{~b})$ & $4 \mathrm{c})$ \\
\hline Incorrect & 1 & 3 & 5 & 13 & 10 & 5 \\
\hline Partially correct & 0 & 0 & 5 & 0 & 0 & 0 \\
\hline Correct & 20 & 18 & 11 & 6 & 3 & 5 \\
\hline No answer & 0 & 0 & 0 & 2 & 8 & 11 \\
\hline Total & 21 & 21 & 21 & 19 & 21 & 21 \\
\hline
\end{tabular}

\section{COGNITIVE CONFLICTS}

In this section we describe the evaluation tasks proposed by the researcher and the results obtained, which allow us to detect cognitive conflicts generated in the learning process.

\section{Tasks Description}

The researcher gave the students the worksheet in Figure 1, so that they could work on it for two 45 min sessions.

The first situation posed is a missing value problem, similar to those that appear in the textbook and where it is asked about the inverse relationship. Task 2 seeks to detect the use of additive relationships in proportional situations (Fernández \& Llinares, 2012). The third problem is centred on the ratio notion. A priori we expect greater complexity to solve this task since it is not a situation that has worked in the instruction received. The last problem, focused on percentages and discounts, seeks to verify whether students connect these with the proportionality relationship. In all the problems, students are expected to justify their responses.

The students worked following the usual distribution in class (sitting in pairs). At the end of the tasks they handed the worksheet individually to the researcher. The answers given to the problems allow us to analyse the constructed knowledge, identify cognitive conflicts and their incidence in the group.

\section{Degree of Correction. Procedures and Arguments}

All students responded to problems 1, 2 and 3. Most of the solutions to problems 1 and 2 are correct. In the case of the third problem, an answer is considered partially correct if only the number of students going by car or walking is calculated. In this case, $52.38 \%$ of the students correctly obtained the number of children who were walking and going by car to school and $23.81 \%$ only calculated one of the amounts correctly. As can be seen in Table 1, problem 4 was more difficult; more than half of the students did not respond to item c) of this problem.

In the first two items, there are more incorrect than correct answers, and in the third item, half of the students who responded, did it correctly and the other half wrongly.

The students developed different types of procedures to solve the problems. In the case of problem 4 , the additive strategy was especially relevant. It was used by $42.11 \%$ of the students in the first item and $38.46 \%$ in the second. Students calculate the discount on the book of 30 euros, $30-25.5=4.5$ and apply a discount of 4.5 euros to the book of 20, answering that they should pay for it, $20-4.5=15.5$. Similarly, assuming that the 


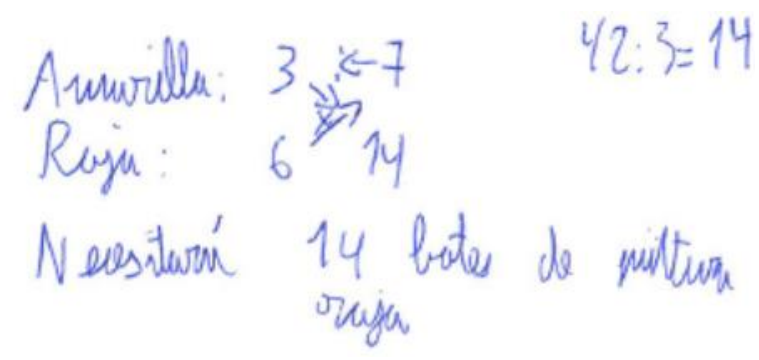

[Yellow; Red; They will need 14 red paint cans]

Figure 2. Correction. A11student's answer to problem 2

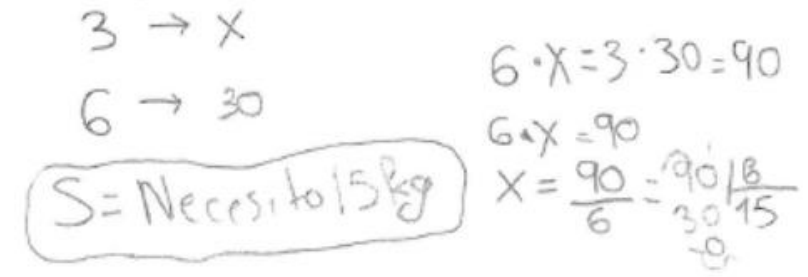

[I need $15 \mathrm{~kg}]$

Figure 3. A17 student's answer to problem 1. (Degenerated rule of three)

discount has been 4.5 euros, they determine that the initial price for the Idhún comic collection should be 34 $+4.5=38.5$ euros.

A procedure based on the relationship "twice the amount of one magnitude corresponds to twice the amount of the other", is found in the answer of some students in problem 2, for example, to determine that Sofia will use 14 red paint cans, because it is twice the 7 of yellow paint that she uses. There is also a procedure that we have called of multiplicative type in problem 4 . For example, once they have determined that the price they will pay for a book of 20 euros is 17 euros, to respond to item b) they consider that if 34 is twice of 17 , then the price of the comic collection, which is now worth 34 euros, should be double 20 euros, that is 40 . To determine the percentage of discount in item c), 4 students of the 10 who answered to this item, used a procedure similar to that of student A11:

$$
\begin{aligned}
& 10 \%=3 \text { because } 3 \times 10=30 \\
& 3: 2=1,5=5 \% ; 4,5=15 \%
\end{aligned}
$$

\section{A $15 \%$}

The unit reduction procedure was used exceptionally by students, being relegated by cross multiplication without expressing the proportion or by the rule of three, based on a tabular or diagrammatic arrangement, involving the unknown but without expressing correctly the proportion.

In Figure 2 we include the A11 student's answer to problem 2. The arrows indicate the numbers that he multiplies and the direction of the division in the procedure used. Figure 3 reproduces the A7 student's response to problem 1 , in which he uses a rule of three without expressing the proportion. In problems 1,2 and 3 some students expressed the proportions that correspond to the proportionality relationship.

As can be seen in Figure 4, the proportions are often written in non-pertinent way, forgetting the equal sign and the operations are chained, appearing meaningless algebraic expressions. All information regarding the frequencies of the procedure types described is included in Table 2. 


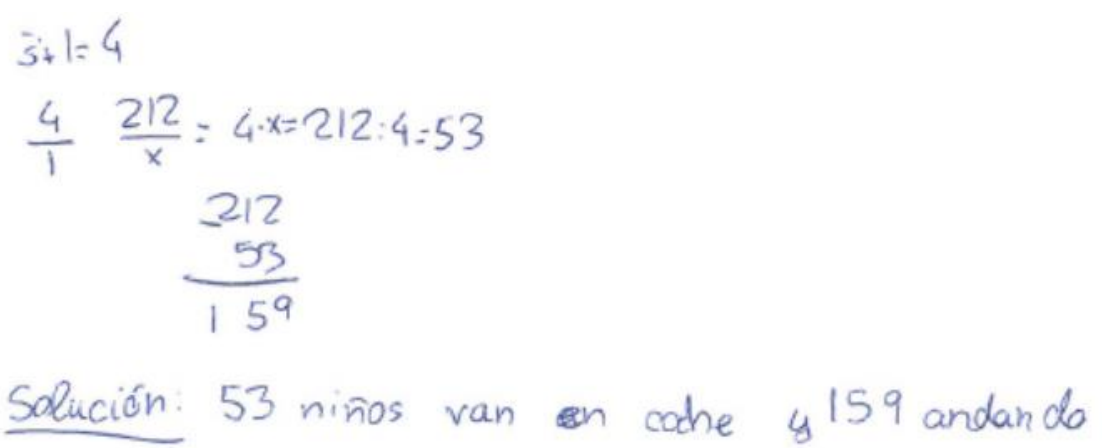

[Solution. 53 children go by car and 157 walking]

Figure 4. A2 student's answer to problem 3

Table 2. Frequencies of procedure types used by the students

\begin{tabular}{ccccccc}
\hline Procedure types & \multicolumn{7}{c}{ Problem } \\
\cline { 2 - 7 } & $\mathbf{1}$ & $\mathbf{2}$ & $\mathbf{3}$ & $\mathbf{4} \mathbf{a})$ & $\mathbf{4} \mathbf{b})$ & $\mathbf{4} \mathbf{c})$ \\
\hline Additive & 0 & 1 & 1 & 8 & 5 & 0 \\
\hline Multiplicative. Double/half relation & 2 & 2 & 0 & 0 & 2 & 4 \\
\hline Cross product. Proportion is not expressed & 3 & 3 & 1 & 8 & 3 & 1 \\
\hline Reduction to the unit & 2 & 0 & 2 & 0 & 0 & 1 \\
\hline Calculation of percentages & 0 & 0 & 0 & 2 & 2 & 0 \\
\hline Degenerated rule of three & 9 & 10 & 10 & 1 & 1 & 4 \\
\hline Rule of three & 1 & 1 & 4 & 0 & 0 & 0 \\
\hline Proportions & 4 & 4 & 3 & 0 & 0 & 0 \\
\hline No answer & 0 & 0 & 0 & 2 & 8 & 11 \\
\hline Total & 21 & 21 & 21 & 21 & 21 & 21 \\
\hline
\end{tabular}

As we can see, most of the students solved the problems through the rule of three and/or establishing proportions. This explains why the tabular or diagrammatic and symbolic register have a great presence in the answers given. Few students justified their responses in the different problems: 5 students in the first, 9 in the second and 11 in the third. The categories of arguments identified in the students' answers are the following:

- Additive. In this category we find arguments similar to that of student A14 developed to justify the solution of problem 2:

- $6+3=9 ; \quad 9-7=2$

- Because first there are 9 cans minus 7 which has used; solution: 2 cans will be needed

- Double-half relation. A12 student's justification for the solution of problem 2 would be included in this category:

- You will need 14 paint cans, because double of 7 is 14 and as it puts double of 3, which is 6 , it is like that.

- Tabular. We refer to those cases in which the student constructs a table with some values of the magnitudes, including the solution to the problem, to justify their relationship of direct proportionality.

- Procedural. In this case the student refers to the procedure followed. For example, student A9 justifies her solution to problem 1 in this way:

- I have applied the rule of three. What I have done has been to multiply in cross 3 by 30, and what has come out I have divided it by 6 . When doing that division the quotient (which is 15) is equal to $x$.

- Formal, if it is based on the ratio of proportionality, proportions or unit value (see Figures 5 and 6). 


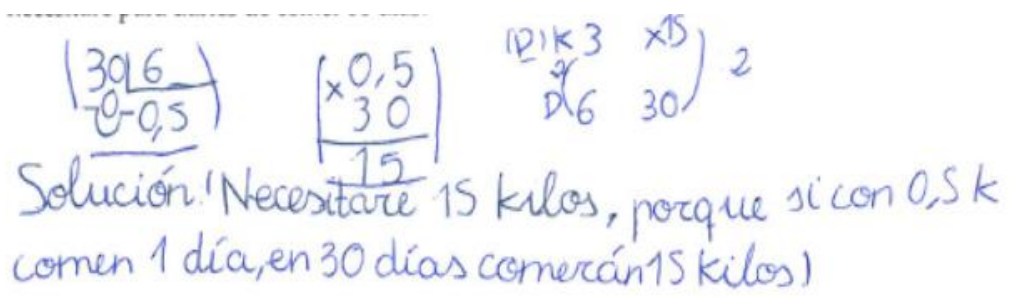

[Solution (I will need 15 kilos, because if with 0.5k they eat 1 day, in 30 days will eat 15 kilos)]

Figure 5. Solution proposed by A12 to problem 1 based on the unit value

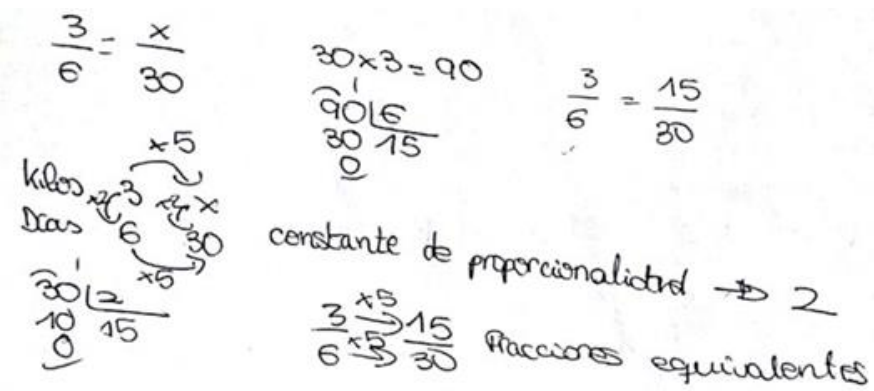

Figure 6. Solution proposed by A21 identifying the proportionality constant

The justifications of additive type were incorrect. Procedural justifications or those of a formal character that aim to validate the procedure correctness are also considered incorrect: for example, student A8 includes as justification in problem 2 :

$$
\text { Because } \frac{6}{3} \text { is equivalent to } \frac{14}{7} \text {. }
$$

We have classified as partially correct those justifications based on double-half relationships or those of the tabular type. In Table 3 we summarize the types of arguments and degrees of correction of the same, for the cases in which the students provided justifications for the solutions.

Table 3. Argument types frequencies and their degree of correction

\begin{tabular}{|c|c|c|c|c|}
\hline \multirow{2}{*}{\multicolumn{2}{|c|}{ Justification }} & \multicolumn{3}{|c|}{ Problem } \\
\hline & & 1 & 2 & 3 \\
\hline \multirow{3}{*}{ Degree of correction } & Incorrect & 2 & 4 & 3 \\
\hline & Partially correct & 2 & 4 & 7 \\
\hline & Correct & 1 & 1 & 1 \\
\hline \multirow{5}{*}{ Type of argument used } & Additive & 0 & 1 & 2 \\
\hline & Double/half relation & 0 & 1 & 0 \\
\hline & Tabular & 1 & 2 & 6 \\
\hline & Procedural & 3 & 2 & 2 \\
\hline & Formal & 1 & 3 & 1 \\
\hline Total & & 5 & 9 & 11 \\
\hline
\end{tabular}

\section{Cognitive Conflicts}

In the OSA theoretical framework, students' errors are interpreted in terms of cognitive semiotic conflicts, that is to say, as mismatches between the institutional meanings of the different objects involved in mathematical practices and the attributed personal meanings. This provides a semiotic explanation for the students' errors. Taking into account the types of mathematical objects involved in student responses, these conflicts are grouped as follows:

- Procedural (wrong procedure performed).

PC1: Do not apply correctly the rule of three.

PC2: Pose the proportion but the different steps in solving the unknown are not stated.

PC3: Compute incorrectly the percentage. 


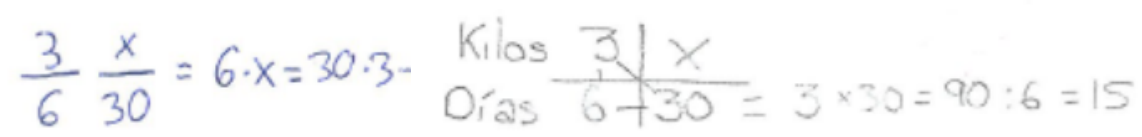

Figure 7. Examples of $\mathrm{PC} 1$ and RC2 conflicts in responses of students A2 and A4

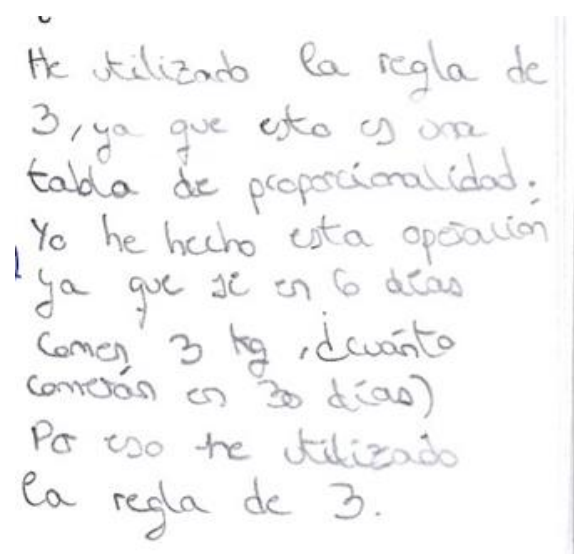

[I have used the rule of 3 , since this is a proportionality table. I have done this operation because if in 6 days they eat $3 \mathrm{~kg}$, how much will they eat in 30 days? That's why I used the rule of 3]

Figure 8. Justification of a student expressing the AC1 argument conflict

$$
\frac{-30,0}{0,5,5}-\frac{20,0}{15,5}+\frac{34}{38,5}
$$

Figure 9. A2 response to problem 4. Example of CC2 conceptual conflict

- Conceptual (inappropriate application of concepts).

$\mathrm{CC} 1$ : Incorrect meaning of the equal sign.

CC2: Do not perceive or correctly interpret the proportionality relationship.

CC3: Confuse quantities of directly proportional magnitudes with its representation in a proportionality table.

- With arguments (incorrect justifications).

$\mathrm{AC1}$ : Use the application of the rule of three as a supporting argument.

AC2: Use the proposition that is intended to justify as an argument.

AC3: Do not justify the proportionality relationship that allows to construct the proportionality table.

- Representational (inappropriate use of language in its various registers).

$\mathrm{RC} 1$ : Omit the equal sign in the proportion.

RC2: Chaining arithmetic or algebraic identities.

RC3: Use the equal sign to incorrectly express connection or dependence between two magnitudes.

RC4: Use arrows or lines as operator (multiplication or division).

In Figures 7-9 we show some examples of these conflicts.

As summarized in Table 4, in general, the categories of conflicts with the greatest presence are the representational in problems 1,2 and 3 , and the conceptual conflict in problem 4 . Within procedural conflicts, the most frequent in all the problems is not to correctly apply the rule of three (PC1) and within the representational ones, to link arithmetic or algebraic identities, using the equal sign as a separator of the steps performed in the task resolution (RC2). 
Table 4. Frequencies of cognitive conflicts in each problem

\begin{tabular}{|c|c|c|c|c|c|}
\hline \multicolumn{2}{|c|}{ Conflicts } & \multicolumn{4}{|c|}{ Problems } \\
\hline & & 1 & 2 & 3 & 4 \\
\hline \multirow{3}{*}{ Procedural } & PC1 & 9 & 9 & 10 & 5 \\
\hline & $\mathrm{PC} 2$ & 1 & 2 & 1 & 1 \\
\hline & PC3 & 0 & 0 & 0 & 2 \\
\hline \multirow{3}{*}{ Conceptual } & $\mathrm{CC} 1$ & 7 & 4 & 2 & 0 \\
\hline & $\mathrm{CC} 2$ & 0 & 1 & 1 & 9 \\
\hline & $\mathrm{CC} 3$ & 1 & 1 & 1 & 0 \\
\hline \multirow{3}{*}{ With arguments } & $\mathrm{AC} 1$ & 3 & 2 & 2 & 0 \\
\hline & $\mathrm{AC} 2$ & 0 & 2 & 1 & 0 \\
\hline & $\mathrm{AC} 3$ & 0 & 1 & 5 & 0 \\
\hline \multirow{4}{*}{ Representational } & CR1 & 3 & 2 & 3 & 1 \\
\hline & CR2 & 10 & 8 & 3 & 3 \\
\hline & CR3 & 4 & 3 & 2 & 4 \\
\hline & CR4 & 3 & 2 & 0 & 0 \\
\hline Tota & & 41 & 34 & 31 & 25 \\
\hline
\end{tabular}

The number of argumentation conflicts is smaller, given that there are few students who justify their responses. When students try to justify their responses, they use the rule of three procedure as an argument (CA1) or adopt a proportionality table as a justification, including the missing value obtained without arguing the proportionality relationship that allows to construct the table (CA3). In addition, in problem 4, 36\% of students do not correctly recognize the proportionality relationship (CC2).

\section{RESULTS OF THE GENERAL DISCUSSION SESSION}

In this section we include the description and analysis of results of the discussion session. The aim was to stimulate the students to reflect on their reasoning during the problem-solving processes, and to motivate that their explanations given to the solutions include mathematical arguments. The dialogues maintained also allow to clarify the nature of cognitive conflicts and the way in which they are addressed.

At the beginning, the researcher began by asking the students if they remembered what does it means that two magnitudes are directly proportional. The students mostly nodded, but had difficulty establishing a precise definition of the concept.

Res.: This course, just before the holidays, you have studied proportionality and percentages. In what ways do you know how to solve proportionality problems?

Students (several at once): By rule of three.

Res.: Okay, rule of three ... Just like that?

There is silence, it seems that students find it difficult to identify another procedure to solve proportionality problems.

\section{A21: We also know unit reduction. I like it more.}

Researcher: Why?

A21: Because I don't understand why the rule of three works.

It is interesting to note that most of the students, in the discussion claim to prefer the rule of three to solve the proportionality problems. However, A21 shows a certain rejection of the procedure stating that it does not understand what sustains it.

Before continuing with the session, the researcher briefly recalled the unit reduction procedure, the rule of three and the notion of proportionality constant. She then distributed the worksheets to each student with the answers they gave to the assignments, noting that, although almost all the solutions were correct, most had not justified their answers. A dialogue was initiated with the students to recognize the proportionality situations and the arguments that allow applying the rule of three procedure that they had mostly followed when solving the problems. 
The researcher asks who wants to go up to the blackboard. The student A10 goes.

A10: First I have made a proportionality table and as it says that with 3 kilograms of corn the hens eat 6 days, I have put the kilograms and the days.

The researcher interrupts.

Res.: What are the directly proportional quantities there?

A10: $3,6, \ldots$

Res.: But what are the magnitudes?

The student A10 and the other students doubt, showing difficulty in identifying the directly proportional quantities in this situation. For that reason the researcher continues:

Res.: Kilograms of corn and number of days my hens eat. These magnitudes are proportional, but, be careful, because they might not be. In this case they are and that is why we can solve the problem as we are doing. We assume that chickens eat the same thing every day.

A10: I have put 3 kilograms and 6 days and as they ask us how many kilograms I need so the hens can eat 30 days I have put 30 and $x$, which is what we do not know. So the first thing I've done is multiply 3 by 30 that gives me 90 and then I have divided by 6 that gives me 15 .

Res.: Do you all agree?

Students generally nod.

Res.: How did you solve it?

Student: Proportionality table.

Student: You have put the $x$, it is the rule of three.

Students identify as method "the elaboration of a proportionality table", and identify the rule of three through the literal symbol $x$ in the table.

The researcher recalls on the proportionality table of the board, the multiplicative relationship between the proportional quantities and points out:

Res.: To apply the rule of three, the magnitudes need to be proportional. If the magnitudes are not proportional, I cannot use it. It can be applied due to how are the fractions that appear here (she indicate in the proportionality table the fractions with numerator the amounts of kilograms of corn and denominator the numbers of days)?

Several students respond "they are equivalent fractions".

Res.: That is, they are equivalent fractions. And, if I have two fractions that are equivalent, what happens to the cross product?

A10: That gives the same result.

At this moment they go to the second problem. The researcher reads it, emphasizing that it is necessary to explain the solution, given that in the individual work almost no student had justified his answer. The student A3 offers to go up to the board to explain his solution.

A3: Well, I've made the rule of three.

Res.: Why can you apply the rule of three to this problem?

A3: Because they are proportional. 
Res.: What magnitudes are proportional?

In the back of the class a student indicates "six and seven", showing confusion between the quantities of the magnitudes and the magnitudes involved in the situation.

A3: They are the cans of red paint and yellow paint.

Res.: Why do they have to be proportional? What does the statement tell us?

A3: That the rooms have to be the same colour.

Res.: Exactly, if I change the proportion of the paintings the tone will not be the same, it will be redder or more yellow.

The student A3 responds appropriately when the researcher suggests that they seek in the context the justification for the proportionality relationship between the magnitudes. At this time the researcher takes the opportunity to remember the concept of proportionality constant, and asks what the proportionality constant in the problem is. The students doubt. Once they identify that the proportionality constant is 2 they continue.

Res.: I'm using twice as much red paint as yellow paint. If I have 7 cans of yellow paint, how many cans of red paint will I need?

Students: Double, 14.

Res.: Why double?

Several students: Because they are in proportion.

Several students: Because if not, the same colour would not come out.

They read the statement of the third problem. Student A20 writes on the board.

A20: I have made a proportionality table to know how many children go first and after walking. I have made 8 divided by 2 which is equal to 212 divided by $x$.

A20 identifies as a procedure "to elaborate the proportionality table" from which he establishes the proportional equation. The researcher tries to link the proportion to the proportional quantities whose quantities form it and identify the unit.

Res.: In order to write this proportion, what magnitudes are you considering to be proportional?

A20: Children and those who go by car.

Res.: But, this number of children is four, why?

A10: Because there are three that go by car plus one that go walking. We make groups of four.

Res.: Well, if we know the number of children who go to school, how can we know the number of children who go by car?

Several students: dividing by four.

Finally, student A19 offers to go up to the blackboard to solve and explain the last problem.

A19: The first thing I have done, as it says that for a book of 30 euros I have paid 25.5 euros, I have done $30-25.5$.

Res.: Well, this 4.5 that you have obtained, what it is?

Students (several): The discount. 
Res.: Very good, the discount. And now?

A19: It says, how much will I pay for a book of 20 euros? As I have presented the discount card, I rest 4 and a half to 20 and it leaves 15 and a half.

Res.: Do you all agree?

A19 has used an additive strategy. The researcher seeks approval or disapproval from the partners.

A10: Well, as it tells me that from a book of 30 euros I have paid 25.5, I have made a rule of three to see what it would cost.

The student A10 argues that the procedure needed to find out how much he should pay for an object of 20 euros is a rule of three. However, he does not explain what means the amounts involved in it.

Res.: According to (she refers to the boy who is on the board) you have written here, the discount they have applied to the book of 30 euros is 4.5 , which is correct. But, you say that the discount will always be the same, it will always be 4.5 euros. Do you think they should discount 4.5 euros the same for a book of 20 euros, than for one of 30 ?

A11: You should make 4.5 percent of 30 and so find out the percentage.

A11 shows a conflict in expressing the part-whole relationship involved in the percentage. The researcher tries to justify why the additive strategy used by A19 is not correct.

Res.: You mean, you should know what percentage of discount is 4.5, right?

A11: Yes, of course.

Res.: We apply the same discount to all your items, but not in the amount of euros. This 4.5 is the discount on 30 euros, how would you know now what is the discount on 20 euros?

A10 interrupts to identify the quantities of the magnitudes that appear in the rule of three by means of the proportionality table.

A10: I have put [he refers to his proportionality table] above what the book costs, 30, below with the discount, 25.5, then I have put 20 and below $x$.

At this moment the teacher of the next class arrives and unfortunately the session is finished.

\section{DISCUSSION}

The commitment of our research with educational practice has led us to focus attention on a real class group that has begun the study of proportionality under an instructional model in which the textbook plays a leading role. The analysis carried out has allows us to connect epistemic and cognitive conflicts generated when students begin the study of proportionality and percentages with an instruction focused on the procedural aspect.

In general, students have difficulties in recognizing proportionality situations and identifying procedures to solve proportionality problems other than the rule of three. This may be due to the central role assigned in the textbook (and by extension in the instruction received) to the proportionality tables as an identifier of the relationship and to the rule of three as a priority procedure to solve this type of problem. As we have observed, opportunities were not offered to distinguish proportional from non-proportional situations, nor was an intuitive approach included (EC2 epistemic conflict).

The students successfully solved problems 1, 2 and 3, but not the problem 4, that was more difficult and had a greater number of incorrect additive strategies (36\% of the students do not correctly recognize the proportionality relationship in this problem; CC2). A possible explanation for this fact should be sought in the least familiarity of the students with the last type of problems and that the conceptual aspect has been neglected in the study of proportionality and percentages. The type of problems proposed and solved by the students were only of missing value (EC5) and the study of percentages is established without connection with proportionality, using only a procedural point of view (EC6). 
The resolution procedure used mostly by the students was the rule of three in its degenerate version: the students set the proportionality table but ignore the "step 2" described in the textbook as part of the procedure consisting in establishing the proportion. This fact may have its origin in the epistemic conflicts EC3 and EC4 described in section 4.2: the rule of three is presented as a means to calculate one of the four values if the other three are known.

The tabular and symbolic registers have a great presence in the students' answers, although the latter is not used properly and representational cognitive conflicts are numerous, especially, linking arithmetic or algebraic identities by using the equal sign as a separator of the steps taken in the task resolution (RC2).

The students did not mostly justify the answers given to the different tasks. When they did, they often used the procedure that should be justified as an argument (AC1) or adopted the proportionality table as justification (AC3). It is not surprising since, as we have identified in section 4, the instruction previously received was focused almost exclusively on procedures, without offering students the possibility to interpret or explain the meaning of the data or the process followed and justify the solutions.

Initially, students confuse quantities of magnitude and directly proportional magnitudes, with proportionality table. For example, when asked by the researcher about the directly proportional quantities in the first problem, the student who had go the board indicated the quantities 3,6 which are the amounts corresponding to the proportional quantities kilograms of corn and number of days. However, as the large group sharing on the solutions progress, this mismatch improves: we observe that in the discussion about the second problem the students begin to identify as directly proportional quantities the red and yellow paint cans and then, in the third problem, there is no difficulty in recognizing children who go walking to school and those who go by car as directly proportional magnitudes.

Students have difficulty with identifying the proportionality constant between directly proportional quantities. In this sense, we mention that the definition of direct proportionality correspondence contained in the textbook is given by means of the scalar relationship, obviating the functional relationship established between magnitudes (EC1). When students begin to understand the functional relationship and the meaning of the proportionality constant, they can use procedures other than the rule of three, such as obtaining the unit value. In this regard, we remember that most of the students had used the rule of three in the resolutions written in their worksheets, but that in the general discussion the students argued the possibility of obtaining the number of red paint cans multiplying by two the number of yellow paint cans, or the number of students who go to school by car by dividing by four the number of students who go walking. As Fernández and Llinares (2012) point out, an indiscriminate use of the rule of three can lead to not developing adequate proportional reasoning, and in particular not distinguishing situations of proportionality from those that are not. In this sense, authors such as Ercole, Frantz and Ashline (2011) describe the unit reduction procedure as an intuitive strategy that should be used as a starting point for the proportionality instruction (p. 483).

In the interaction of the group with the researcher, students begin to justify the procedures and propositions used, connecting the different objects involved in a situation of proportionality, in particular linking the rule of three, the equivalence of fractions and the relationship of direct proportionality. They also begin to identify the presence and need for an explanation of this relationship ("the magnitudes number of red paint cans and number of yellow paint cans are directly proportional since the rooms have to be the same colour"). Burgos and Godino (2018) conclude that an appropriate degree of dialogue, interaction and communication in the introduction of proportionality allows to detect intuitive and natural strategies, and those that students develop with little guidance from the teacher (for example, the reduction to unit strategy) and increases the students' degree of involvement and interest.

Several studies emphasize the importance of argumentation and its connection with conceptual understanding from an early age (Lin \& Tsai, 2016; Stylianides; Bieda \& Morselli, 2016). Promoting the use of arguments requires a change in the nature of speech in the mathematics class. "In an expected classroom where the young students develop skills of persuasive arguments, instead of being an audience for the teachers' reasoning, but needs to provide students the opportunities to learn such argumentation." (Lin, 2018, p. 1174).

Communicating and arguing about situations in which relations of proportionality (and nonproportionality) appear as a didactic strategy, will make it possible to give meaning to the procedures and symbols used by students when they raise a proportion. Along this line, Gairín and Escolano (2009), and Oller (2012) point to the prior identification of regularity conditions and the meaning of ratios. However, it is necessary to design and implement new research cycles (in the same educational level and in higher ones) that 
promote in students the application of higher levels of algebraic reasoning in solving proportionality problems, in particular the application of the linear function notion and resolution techniques based on the properties of these functions, which are characteristic of a higher level of algebrization (Godino et al., 2017).

The traditional textbook proposes a selection and sequencing of a system of operative, discursive and normative practices, applying an essentially transmissive didactical model, which is inherent in the presentation of the content in this type of resource. The teacher should be in charge of developing a didactical model in which the solution of problem-situations proposed by the textbook can be done in a dialogical and cooperative manner.

\section{ACKNOWLEDGEMENT}

Research carried out as part of the research project PID2019-105601GB-I00, with support from the Research Group FQM-126 of the Andalusian Research Plan (Junta de Andalucía, Spain).

\section{Disclosure statement}

No potential conflict of interest was reported by the authors.

\section{Notes on contributors}

María Burgos - Universidad de Granada, Spain.

Juan D. Godino - Universidad de Granada, Spain.

\section{REFERENCES}

Artigue, M. (2011). L’ingénierie didactique: un essai de synthèse. In C. Margolinas, M. Abboud-Blanchard, L. Bueno-Ravel, N. Douek, A. Fluckiger, P. Gibel, F. Vandebrouck, \& F. Wozniak (Eds.), En amont et en aval des ingénieries didactiques (pp. 225-237). Grenoble: La pensée Sauvage.

Burgos, M., \& Godino, J. D. (2018). Trabajando juntos situaciones introductorias de razonamiento proporcional en primaria. Análisis de una experiencia de enseñanza centrada en el profesor, en el estudiante y en el contenido. Bolema, 33(63), 389-410. https://doi.org/10.1590/1980-4415v33n63a19

Burgos, M., \& Godino, J.D. (2019) Emergencia de razonamiento proto-algebraico en tareas de proporcionalidad en estudiantes de primaria. Educación Matemática, 31(3), 117-150 https://doi.org/10.24844/EM3103.05

Burgos, M., Castillo, M. J., Beltrán-Pellicer, P., Giacomone, B., \& Godino, J. D. (2020). Análisis didáctico de una lección sobre proporcionalidad en un libro de texto de primaria con herramientas del enfoque ontosemiótico. Bolema, 34(66) (to appear).

Cramer, K., \& Post, T. (1993). Connecting research to teaching proportional reasoning. Mathematics Teacher, 86(5), 404-407.

Dole, S., \& Shield, M. (2008). The capacity of two Australian eighth-grade textbooks for promoting proportional reasoning. Research in Mathematics Education, 10(1), 19-35. https://doi.org/10.1080/ 14794800801915863

Fernández, C., \& Llinares, S. (2011). De la estructura aditiva a la multiplicativa: Efecto de dos variables en el desarrollo del razonamiento proporcional. Infancia y Aprendizaje, 34(1), 67-80. https://doi.org/10.1174/021037011794390111

Fernández, C., \& Llinares, S. (2012) Características del desarrollo del razonamiento proporcional en la Educación Primaria y Secundaria. Enseñanza de las Ciencias, 30(1), 129-142. https://doi.org/10.5565/rev/ec/v30n1.596

Fernandez, P., Caballero, P., \& Fernandez, J. A. (2013). ¿Yerra el niño o yerra el libro de matemáticas? Números. Revista de Didáctica de las Matemáticas, 83, 131-148.

Ferrero, L., Martín, P., Alonso, G., \& Bernal, E. (2015) Matemáticas 6. Aprender es crecer. Madrid: Grupo Anaya, S. A.

Fielding-Wells, J., Dole, S., \& Makar, K. (2014). Inquiry pedagogy to promote emerging proportional reasoning in primary students. Mathematics Education Research Journal, 26, 47-77. https://doi.org/10.1007/s13394-013-0111-6 
Gairín, J. M., \& Escolano, R. (2009). Proporcionalidad aritmética: buscando alternativas a la enseñanza tradicional. Suma: Revista sobre Enseñanza y Aprendizaje de las Matemáticas, 62, 35-48.

Godino, J. D. Batanero, C., \& Font, V. (2019). The onto-semiotic approach: implications for the prescriptive character of didactic. For the Learning of Mathematics, 39(1), 37-42.

Godino, J. D. Beltrán-Pellicer, P., Burgos, M., \& Giacomone, B. (2017) Significados pragmáticos y configuraciones ontosemióticas en el estudio de la proporcionalidad. In J. M. Contreras, P. Arteaga, G. R. Cañadas, M. M. Gea, B. Giacomone \& M. M. López-Martín (Eds.), Actas del segundo Congreso International Virtual sobre el Enfoque Ontosemiótico del conocimiento y la instrucción matemáticos. Available in www.enfoqueontosemiotico.ugr.es/civeos.html

Godino, J. D., Batanero, C., \& Font, V. (2007). The onto-semiotic approach to research in mathematics education. ZDM, 39(1-2), 127-135. https://doi.org/10.1007/s11858-006-0004-1

Godino, J. D., Rivas, H., Arteaga, P., Lasa, A., \& Wilhelmi, M. R. (2014) Ingeniería didáctica basada en el enfoque ontológico-semiótico del conocimiento y la instrucción matemáticos. Recherches en Didactique des Mathématiques, 34(2/3), 167-200.

Guacaneme, E. (2001). Estudio didáctico de la proporción y la proporcionalidad: Una aproximación a los aspectos matemáticos formales y a los textos escolares de matemáticas (Unpublished Master Dissertation). Universidad del Valle, Cali, Colombia.

Hilton, A., Hilton, G., Dole, S., \& Goos, M. (2016) Promoting middle school students' proportional reasoning skills through an ongoing professional development programme for teachers. Educational Studies in Mathematics, 92(2), 193-219. https://doi.org/10.1007/s10649-016-9694-7

Karplus, R., Pulos, S., \& Stage, E. (1993). Early adolescents proportional reasoning on "rate" problems. Educational Studies in Mathematics, 14(3), 219-233. https://doi.org/10.1007/BF00410539

Kelly, A., Lesh, R., \& Baek, J. (Eds.) (2008). Handbook of design research in methods in education. Innovations in science, technology, engineering, and mathematics learning and teaching. New York, NY: Routledge.

Lamon, S. (2007). Rational number and proportional reasoning. Toward a theoretical framework for research. In F. K. Lester (Ed.). Second handbook of research on mathematics teaching and learning. (pp. 629667). Charlotte, NC: NCTM and IAP.

Lesh, R., Post, T., \& Behr, M. (1988). Proportional reasoning. In J. Hiebert \& M. Behr (Eds.), Number concepts and operations for the middle grades (pp. 93-118). Reston, VA: NCTM.

Lin, P. J. (2018). The development of students' mathematical argumentation in a primary classroom. Educação \& Realidade, 43(3), 1171-1192. https://doi.org/10.1590/2175-623676887

Lin, P. J., \& Tai, W-H. (2016). Enhancing students' mathematical conjecturing and justification in third-grade classrooms: the sum of even/odd numbers. Journal of Mathematics Education, 9(1), 1-15.

Modestou, M., \& Gagatsis, A. (2010). Cognitive and metacognitive aspects of proportional reasoning. Mathematical Teaching and Learning, 12(1), 36-53. https://doi.org/10.1080/10986060903465822

Oller, A. M. (2012). Proporcionalidad aritmética: Una propuesta didáctica para alumnos de secundaria. Tesis doctoral. Universidad de Valladolid, Spain.

Rezat, S. (2010). The utilization of mathematics textbooks as instruments of learning. In V. Durand-Guerrier, S. Soury-Lavergne \& F. Arzarello (Eds.), Proceedings of CERME 6, Working Group 7 (pp. 1260-1269). Lyon: Institute National de Recherche Pédagogique.

Riley, K. (2010). Teachers' understanding of proportional reasoning. In P. Brosnan, D. B. Erchick, \& L. Flevares (Eds.), Proceedings of the $32^{\text {nd }}$ annual meeting of the North American Chapter of the International Group for the Psychology of Mathematics Education (pp. 1055-1061). Columbus, OH: The Ohio State University.

Sánchez, E. A. (2013). Razones, proporciones y proporcionalidad en una situación de reparto: Una mirada desde la teoría antropológica de lo didáctico. Revista Latinoamericana de Investigación en Matemática Educativa, 16(1), 65-97.

Singh, P. (2000) Understanding the concepts of proportion and ratio constructed by two grade six students, Educational Studies in Mathematics, 43(3), 271-292. https://doi.org/10.1023/A:1011976904850

Streefland, L. (1985) Search for roots of ratio: some thoughts on the long term learning process (towards... a theory) part II: the outline of the long term learning process. Educational Studies in Mathematics, 16(1), 75-94. https://doi.org/10.1007/BF00354884 
Stylianides, A., Beda, K., \& Morselli, F. (2016) Proof and Argumentation in Mathematics Education Research. In A. Gutiérrez, G. Leder \& Boero, P. (Eds.). Second Handbook of Research on the Psychology of Mathematics Education: the journey continues (pp. 315-351). Rotterdam: Sense Publishing. https://doi.org/10.1007/978-94-6300-561-6_9

http://www.iejme.com 